\title{
Erratum to: A comparison of changes in river runoff from multiple global and catchment-scale hydrological models under global warming scenarios of $1^{\circ} \mathrm{C}$, $2^{\circ} \mathrm{C}$ and $3{ }^{\circ} \mathrm{C}$
}

\author{
Simon N. Gosling ${ }^{1}$ • Jamal Zaherpour ${ }^{1}$. \\ Nick J. Mount ${ }^{1}$ - Fred F. Hattermann ${ }^{2}$. \\ Rutger Dankers $^{3}$ • Berit Arheimer ${ }^{4}$ Lutz Breuer ${ }^{5,6}$. \\ Jie Ding ${ }^{7,8}$ • Ingjerd Haddeland ${ }^{9}$. Rohini Kumar ${ }^{10}$ • \\ Dipangkar Kundu ${ }^{11}$ • Junguo Liu ${ }^{7,12}$. \\ Ann van Griensven ${ }^{13,14}$ • Ted I. E. Veldkamp ${ }^{15}$. \\ ${\text { Tobias } \text { Vetter }^{2} \cdot \text { Xiaoyan Wang }^{16} \cdot \text { Xinxin Zhang }}^{12}$
}

Published online: 9 December 2016

(C) Springer Science+Business Media Dordrecht 2016

\section{Erratum to: Climatic Change \\ DOI 10.1007/s10584-016-1773-3}

In the initial online publication, a middle initial "J." was added to the name of second author Jamal Zaherpour. This middle initial should not be there. The original publication has now been corrected as well.

The online version of the original article can be found at http://dx.doi.org/10.1007/s10584-016-1773-3.

The original article was corrected.

\section{Simon N. Gosling}

simon.gosling@nottingham.ac.uk

School of Geography, University of Nottingham, Nottingham NG7 2RD, UK

2 Potsdam Institute for Climate Impact Research, Telegrafenberg, Potsdam A62 14473, Germany

3 Met Office, Exeter, UK

4 Swedish Meteorological and Hydrological Institute (SMHI), Norrköping 60176, Sweden

5 Institute for Landscape Ecology and Resources Management (ILR), Research Centre for BioSystems, Land Use and Nutrition (iFZ), Justus Liebig University, Giessen, Germany 
6 Centre for International Development and Environmental Research (ZEU), Justus Liebig University, Giessen, Germany

7 School of Environmental Science and Engineering, South University of Science and Technology of China, Shenzhen 518055, China

8 Institute of Water Resources Management, Hydrology and Agricultural Hydraulic Engineering, Leibniz Hannover University, Hannover 30167, Germany

$9 \quad$ Norwegian Water Resources and Energy Directorate, Oslo, Norway

10 UFZ-Helmholtz Centre for Environmental Research, Leipzig, Germany

11 Department of Environmental Sciences, Faculty of Agriculture and Environment, The University of Sydney, Sydney, Australia

12 School of Nature Conservation, Beijing Forestry University, Beijing 10083, China

13 Department of Hydrology and Hydraulic Engineering, Vrije Universiteit Brussel, Brussels, Belgium

14 UNESCO-IHE Institute for Water Education, Delft, Netherlands

15 Vrije Universiteit, Institute for Environmental Studies (IVM), Amsterdam, Netherlands

16 State Key Laboratory of Hydrology-Water Resources and Hydraulic Engineering, Center for Global Change and Water Cycle, Hohai University, Nanjing 210098, China 